\title{
BMJ open Is teenage pregnancy an obstetric risk in a welfare society? A population-based study in Finland, from 2006 to 2011
}

\author{
Suvi Leppälahti, ${ }^{1}$ Mika Gissler, ${ }^{2}$ Maarit Mentula, ${ }^{1}$ Oskari Heikinheimo ${ }^{1}$
}

To cite: Leppälahti S, Gissler M, Mentula M, et al. Is teenage pregnancy an obstetric risk in a welfare society? A population-based study in Finland, from 2006 to 2011. BMJ Open 2013;3 e003225. doi:10.1136/ bmjopen-2013-003225

- Prepublication history for this paper is available online. To view these files please visit the journal online (http://dx.doi.org/10.1136/ bmjopen-2013-003225).

Received 14 May 2013 Revised 29 June 2013 Accepted 24 July 2013
${ }^{1}$ Department of Obstetrics and Gynecology/Kätilöopisto Hospital, University of Helsinki and Helsinki University Central Hospital, Helsinki, Finland

${ }^{2} \mathrm{THL}$ National Institute for Health and Welfare, Helsinki, Finland

\section{Correspondence to}

Dr Oskari Heikinheimo; oskari.heikinheimo@helsinki. fi

\section{ABSTRACT \\ Objective: To assess obstetric outcomes in teenage pregnancies in a country with a low teenage delivery rate and comprehensive high-quality prenatal care.}

Design: Retrospective population-based register study. Setting: Finland.

Participants: All nulliparous teenagers (13-15 years $(n=84), 16-17$ years $(n=1234), 18-19$ years $(n=5987))$ and controls (25-year-old to 29-year-old women $(\mathrm{n}=51$ 142)) with singleton deliveries in 2006-2011.

Main outcome measures: Risk of adverse obstetric outcomes adjusted for demographic factors and clinically relevant pregnancy complications, with main focus on maternal pregnancy complications.

Results: Teenage mothers were more likely than controls to live in rural areas $(16 \% \quad(n=1168)$ vs $11.8 \%$ $(n=6035))$, smoke $(36.4 \%(n=2661)$ vs $7 \%(n=3580))$ and misuse alcohol or drugs $(1.1 \%$ ( $n=82)$ vs $0.2 \%$ $(n=96) ; p<0.001$ for all). Teenagers made a good mean number of antenatal clinic visits (16.4 vs 16.5), but were more likely to have attended fewer than half of the recommended visits $(3 \%(n=210)$ vs $1.4 \%(n=716))$. Teenagers faced increased risks of several obstetric complications, for example, anaemia (adjusted OR 1.8, $95 \% \mathrm{Cl} 1.6$ to 2.1 ), proteinuria (1.8, 1.2 to 2.6$)$, urinary tract infection (UTI; 2.9, 1.8 to 4.8 ), pyelonephritis $(6.3,3.8$ to 10.4$)$ and eclampsia (3.2, 1.4 to 7.3 ), the risks increasing with descending age for most outcomes. Elevated risks of pre-eclampsia $(3.7,1.5$ to 9.0$)$ and preterm delivery $(2.5,1.2$ to 5.3$)$ were also found among 13-year-olds to 15-year-olds. However, teenage mothers were more likely to have vaginal delivery $(1.9,1.7$ to 2.0$)$ without complications Inadequate prenatal care among teenagers was a risk factor of eclampsia (12.6, 2.6 to 62.6), UTI $(5.8,1.7$ to 19.7) and adverse neonatal outcomes.

Conclusions: Pregnant teenagers tended to be socioeconomically disadvantaged versus controls and faced higher risks of various pregnancy complications. Special attention should be paid to enrolling teenagers into adequate prenatal care in early pregnancy.

\section{INTRODUCTION}

Pregnancy during teenage years is associated with socioeconomic and health inequalities as regard both mother and child, ${ }^{1-5}$

\section{ARTICLE SUMMARY}

Article focus

- Teenage pregnancy is associated with maternal anaemia and preterm birth. Association with other adverse obstetric outcomes, especially maternal complications, is less clear.

- Adequate antenatal care among teenagers has been shown to decrease adverse neonatal outcomes, but comprehensive care to all women was not offered in the previous study settings.

- We examined age-specific risks of adverse obstetric outcomes among teenagers, focusing on maternal pregnancy complications and the role of inadequate antenatal care.

\section{Key messages}

- In addition to a higher risk of anaemia, elevated risks of urinary tract infection (UTI), pyelonephritis, proteinuria and eclampsia were found among teenagers as well as pre-eclampsia and preterm delivery among the youngest girls.

- Inadequate antenatal care may place teenagers at markedly elevated risks of UTI, eclampsia and adverse neonatal outcomes even in a welfare society offering high-quality care to all pregnant women.

Strengths and limitations of this study

- The current study was nationwide, giving a realistic reflection of the situation regarding obstetric challenges among all teenage pregnancies during the study period.

- We were able to investigate various factors that have been sparsely reported in connection with teenage pregnancies, including proteinuria, UTI and pyelonephritis during pregnancy, fear of childbirth and pain relief during delivery.

- Our study was retrospective and we could not look at the socioeconomic or educational status of women.

including higher risks of deprivation, ${ }^{2}$ behavioural and emotional difficulties, ${ }^{2}$ maltreatment, ${ }^{1}$ morbidity ${ }^{1}$ and premature mortality. ${ }^{1}{ }^{4}$ Therefore, it is a global concern. Although most pronounced in developing countries, teenage pregnancy remains a significant problem in the developed world too. 
The incidence of teenage pregnancy ending in delivery varies widely, with Nordic countries having comparatively low rates: 6/1000 in Sweden ${ }^{6}$ and 9/1000 in Finland, ${ }^{6}$ compared with 24/1000 in England and $\mathrm{Wales}^{7}$ and $34 / 1000$ in the USA in $2010 .^{8}$

Obstetric risks are often divided into categories of maternal complications, mode of delivery and its complications and neonatal outcome. Teenage pregnancies are associated with maternal anaemia, ${ }^{9-12}$ hypertensive problems ${ }^{13-15}$ and preterm birth, ${ }^{16-19}$ while low risks as regard delivery complications have been reported in studies carried out in industrialised countries. ${ }^{9-12} 19$ However, results concerning several adverse outcomes vary largely, possibly as a result of the great number of confounding factors. Poor socioeconomic conditions, ${ }^{1}{ }^{9} 10$ risky health behaviour, ${ }^{9}{ }^{12}$ inadequate prenatal care ${ }^{18} 2021$ and biological immaturity ${ }^{16-18}$ have been suggested as possible explanations for adverse obstetric outcomes.

Although the issue of teenage pregnancy has been widely studied, a consensus of opinion on obstetric risks is lacking. Comprehensive, age-specific studies concerning maternal complications remain sparse. ${ }^{9}{ }^{17}$ In addition, the role of prenatal care in regard to these problems is not well established. The objective of the current study was to investigate the risks of adverse obstetric outcomes in teenagers in a country with a low rate of adolescent births and comprehensive high-quality prenatal care, with special focus on maternal complications during pregnancy. Second, we aimed to focus on the effect on these outcomes of a low number of visits to antenatal clinics.

\section{MATERIAL AND METHODS}

\section{Study population}

We identified all childbirths ( $\mathrm{n}=354$ 833, of which 349531 were singleton births) between 2006 and 2011 in Finland using the national Medical Birth Register (MBR). Only singleton pregnancies of nulliparous women $(n=97838)$ were included. Cases of major congenital anomaly (defined as major anatomical anomaly, chromosomal anomaly or congenital hypothyroidism ${ }^{22}$ were excluded $(\mathrm{n}=4149)$. After exclusion, there was a total of 7305 singleton childbirths among 13-19-year-old nulliparous girls and women, further divided into three groups: 13-year-olds to 15-year-olds $(\mathrm{n}=84), 16$-year-olds to 17-year-olds $(\mathrm{n}=1234)$ and 18-year-olds to 19-year-olds $(\mathrm{n}=5987)$. Singleton deliveries $(n=51142)$ among women aged 25-29 years served as reference material. Women with histories of abortion and miscarriage $(\mathrm{n}=11703,20.1 \%)$ were included.

\section{Data collection}

The study data were obtained from the MBR and the Hospital Discharge Register (HDR), maintained by the National Institute for Health and Welfare. Reporting to these national registers is obligatory and the data have been shown to be valid and to reflect good coverage. ${ }^{23}$
Data for the MBR were collected at all maternity hospitals in Finland. ${ }^{24}$ It covered all live births and stillbirths with a birth weight of $500 \mathrm{~g}$ or more or with a gestational age of 22 weeks or more. The HDR contains information on all inpatient periods in public and private hospitals and outpatient visits in the public sector. We collected the data separately for pregnancy and delivery (delivery complications include diagnoses reported from the start of delivery until 42 days postpartum). Each complication was noted once per woman.

\section{Study variables}

The choice of study variables was based on previous literature and clinical relevance. All study variables are listed with International Classification of Diseases-10 codes, unless derived from the MBR in a separate check-box

\section{Maternal outcomes}

Anaemia (haemoglobin below $100 \mathrm{~g} / \mathrm{L}$ ), pregnancyinduced hypertension (PIH; O13, O16), pre-eclampsia (O14), eclampsia, proteinuria (O12 excluding O12.0), gestational diabetes, intrahepatic cholestasis of pregnancy (O26.6), placenta praevia, sexually transmitted infections (Chlamydia trachomatis (A56), Neisseria gonorrhoeae and syphilis (A51-A54)), urinary tract infection (UTI; N30, N34, N39.0, O23.1-O23.4, O23.9), pyelonephritis (N10, N12, O23.0), chorioamnionitis (O41.1), bleeding in early pregnancy (O20) and fear of childbirth (O99.80).

\section{Delivery outcomes}

Mode of delivery (vaginal delivery, vaginal breech delivery, assisted vaginal delivery (vacuum extraction or forceps) and caesarean section (elective, urgent and emergency) ), induction of labour, use of oxytocin, episiotomy, pain relief during delivery (regional anaesthesia, other medication and non-medical pain relief), anal sphincter rupture, shoulder dystocia, placental abruption, uterine curettage, abnormal bleeding during (O67) and after delivery (O72), uterine rupture (O71.0-O71.1) and postpartum infection (O85, O86, N71, N72).

\section{Neonatal outcomes}

Preterm birth (extremely preterm ( $<28$ weeks) and preterm $(<37$ weeks of gestation) $)$, birth weight adjusted for gestational age according to the Finnish fetal growth curves $^{25}$ (divided into small-for-gestational-age (SGA, defined as <-2 SD), average-for-gestational-age and large-for-gestational age(defined as $>+2 \mathrm{SD}$ ), 5-min Apgar score below 7, cord blood $\mathrm{pH}$ below 7.05 at birth, resuscitation of the newborn, use of a respirator, use of antibiotics, admission to a neonatal intensive care unit, stillbirth (delivery of a stillborn at 22 weeks of gestation or later) and neonatal death (death of a live-born at 0-6 days of age).

Demographic factors are presented in table 1. Of these, alcohol or drug misuse during pregnancy (Z72.1Z72.2), pre-existing diabetes (E10-E12, O24.0-O24.3) and pre-existing hypertension (I10, O10-O11) were 
derived from the HDR and other variables from the MBR.

The area of residence at the time of delivery was divided into urban, densely populated or rural according to national classification by Statistics Finland. ${ }^{26}$ Prepregnancy body mass index was calculated on the basis of height and weight measures reported by the pregnant women.

Adequacy of prenatal care was calculated on the basis of the recommended number of antenatal clinic visits in Finland (13-17 visits in full-term pregnancies) ${ }^{27}$ adjusted for gestational age at birth. Inadequate prenatal care was defined as attendance at fewer than half of the recommended number of visits.

\section{Statistical analysis}

To assess differences between age groups, the $\chi^{2}$ test and Fisher's exact test were used as appropriate. A p value $<0.05$ was defined as statistically significant. The estimated risks (unadjusted and adjusted ORs with their 95\% CIs) of adverse outcomes were calculated using binary logistic regression. Our basic multivariate model included all demographic factors presented in table 1 (except for history of spontaneous abortions, which was used for preterm birth only) and adequacy of prenatal care. Pregnancy complications were added to the model when found to be clinically relevant. Variables were removed from the model when necessary as a result of small numbers of cases.

A subgroup analysis was carried out including only teenagers, dividing the group into those with inadequate and adequate prenatal care (reference group). The risks were analysed using binary logistic regression. We used the basic multivariate model (see above), excluding preexisting hypertension and diabetes due to the small numbers of cases.

To minimise bias, we used list-wise deletion in logistic regression analysis when data were missing. The percentages of missing cases as regard demographic factors are shown in table 1.

IBM SPSS statistics V.19.0 and V.20.0 for Windows were used for the statistical analyses.

\section{RESULTS}

\section{Demographics}

All the demographic characteristics of the teenagers versus the reference women differed significantly, except for pre-existing diabetes (table 1). Pregnant teenagers were more likely to be single, live in a rural area, smoke and be diagnosed with misuse of alcohol or drugs during pregnancy. Pre-existing hypertension was more common in the reference group.

All groups showed a good mean number of visits to an antenatal clinic (table 2). However, teenagers started

Table 1 Demographic characteristics according to age group (years)

\begin{tabular}{|c|c|c|c|c|c|c|}
\hline & $13-15$ & $16-17$ & $18-19$ & All teenagers & $25-29$ & $\begin{array}{l}\text { p Value* } \\
\text { for difference }\end{array}$ \\
\hline$N$ & 84 & 1234 & 5987 & 7305 & 51142 & \\
\hline \multicolumn{7}{|l|}{ Cohabitation status } \\
\hline Married/cohabiting & $13(15.5)$ & $598(48.5)$ & $4248(71.0)$ & $4859(66.5)$ & $45262(88.5)$ & $<0.001$ \\
\hline Single & $45(53.6)$ & 471 (38.2) & $1132(18.9)$ & $1644(22.5)$ & $2608(5.1)$ & \\
\hline Missing data & $26(30.9)$ & 165 (13.3) & $607(10.1)$ & $802(11.0)$ & $3272(6.4)$ & \\
\hline \multicolumn{7}{|l|}{ Type of residence } \\
\hline Urban & 52 (61.9) & $820(66.5)$ & $3980(66.5)$ & $4852(66.4)$ & $37589(73.5)$ & $<0.001$ \\
\hline Densely populated & $14(16.7)$ & $185(15.0)$ & $1050(17.5)$ & $1249(17.1)$ & $7313(14.3)$ & \\
\hline Rural & $16(19.0)$ & $222(18.0)$ & $930(15.5)$ & $1168(16.0)$ & $6035(11.8)$ & \\
\hline Missing data & $2(2.4)$ & $7(0.5)$ & $27(0.5)$ & $36(0.5)$ & $205(0.4)$ & \\
\hline \multicolumn{7}{|l|}{ Smoking during pregnancy } \\
\hline Yes & 28 (33.3) & $506(41.3)$ & $2127(35.5)$ & $2661(36.4)$ & $3580(7.0)$ & $<0.001$ \\
\hline Quit during first trimester & $11(13.1)$ & $157(12.7)$ & $725(12.1)$ & $893(12.2)$ & $3324(6.5)$ & \\
\hline Missing data & $6(7.1)$ & $37(3.0)$ & $171(2.9)$ & $214(2.9)$ & $921(1.8)$ & \\
\hline Alcohol or drug misuse during pregnancy & $3(3.6)$ & $14(1.1)$ & $65(1.1)$ & $82(1.1)$ & $96(0.2)$ & $<0.001$ \\
\hline \multicolumn{7}{|l|}{ BMI before pregnancy } \\
\hline Underweight $†$ & $16(19.0)$ & $155(12.6)$ & $57(9.6)$ & $228(10.3)$ & $1841(3.6)$ & $<0.001$ \\
\hline Obese & $109(1.3)$ & $63(5.1)$ & $395(6.6)$ & $567(6.3)$ & $4347(8.5)$ & \\
\hline Missing data & $6(7.1)$ & $57(4.6)$ & $174(2.9)$ & 237 (3.2) & $1074(2.1)$ & \\
\hline History of spontaneous abortion(s) & $2(2.4)$ & $51(4.1)$ & 479 (8.0) & $532(7.3)$ & $5984(11.7)$ & $<0.001$ \\
\hline Pre-existing hypertension & $0(0)$ & $1(0.1)$ & $6(0.1)$ & $7(0.1)$ & $102(0.2)$ & 0.026 \\
\hline Pre-existing diabetes & $0(0)$ & $7(0.6)$ & $42(0.7)$ & $49(0.7)$ & $358(0.7)$ & 0.834 \\
\hline \multicolumn{7}{|c|}{$\begin{array}{l}\text { Data expressed as } n(\%) \text {. } \\
{ }^{*} \mathrm{p} \text { Values refer to differences between all the age groups. } \\
\dagger \mathrm{BMI}<18.5 \mathrm{~kg} / \mathrm{m}^{2} \text {. } \\
\text { †BMI } \geq 30 \mathrm{~kg} / \mathrm{m}^{2} \text {. } \\
\mathrm{BMI}, \text { body mass index. }\end{array}$} \\
\hline
\end{tabular}


Table 2 Prenatal care according to age group (years)

\begin{tabular}{|c|c|c|c|c|c|c|}
\hline & $13-15$ & $16-17$ & $18-19$ & All teenagers & $25-29$ & $\begin{array}{l}\text { p Value* } \\
\text { for difference }\end{array}$ \\
\hline $\mathrm{N}$ & 84 & 1234 & 5987 & 7305 & 51142 & \\
\hline All antenatal visits (mean $\pm S D)$ & $14.6 \pm 6.0$ & $16.1 \pm 5.8$ & $16.5 \pm 5.3$ & $16.4 \pm 5.4$ & $16.5 \pm 4.7$ & $<0.001$ \\
\hline Hospital polyclinic visits (mean \pm SD) & $4.3 \pm 2.3$ & $3.7 \pm 2.9$ & $3.1 \pm 2.7$ & $3.2 \pm 2.8$ & $2.7 \pm 2.5$ & $<0.001$ \\
\hline First antenatal visit, gestational weeks & $18.8 \pm 9.0$ & $12.6 \pm 7.2$ & $10.2 \pm 5.0$ & $10.7 \pm 5.6$ & $9.0 \pm 3.1$ & $<0.001$ \\
\hline $\begin{array}{l}\text { First antenatal visit } \geq 20 \text { gestational weeks } \\
\text { Low attendance }(\%)\end{array}$ & 43 (51.2) & $192(15.6)$ & $358(6.0)$ & $593(8.1)$ & $728(1.4)$ & $<0.001$ \\
\hline$<50 \%$ of expected visits & $4(4.9)$ & $65(5.4)$ & $141(2.4)$ & $210(3.0)$ & $691(1.4)$ & $<0.001$ \\
\hline First trimester ultrasonographic screening & $30(35.7)$ & $671(54.4)$ & $3733(62.4)$ & $4434(60.7)$ & $37429(73.2)$ & $<0.001$ \\
\hline Second trimester ultrasonographic screening & $45(53.6)$ & $850(68.9)$ & 4299 (71.8) & $5194(71.1)$ & $39620(77.5)$ & $<0.001$ \\
\hline
\end{tabular}

their prenatal care significantly later in pregnancy. All teenage groups were also more likely to show a significantly lower attendance rate.

\section{Pregnancy complications}

Significantly increased risks of anaemia, eclampsia, proteinuria, UTI and pyelonephritis were noted among the teenagers. The youngest group of teenagers (13-year-olds to 15-year-olds) had an elevated risk of pre-eclampsia and a small excess risk was also noted among 18-year-olds to 19-year-olds after controlling for confounding factors (table 3). The frequency of gestational diabetes $(5.3 \%$ $(\mathrm{n}=385)$ vs $8.2 \% \quad(\mathrm{n}=4173)$, adjusted OR $0.7,95 \%$ CI 0.6 to $0.7)$ and placenta praevia $(0.04 \%(\mathrm{n}=3)$ vs $0.3 \% \quad(\mathrm{n}=161)$, adjusted OR $0.1,0.01$ to 0.8 ) was lower among 13-year-olds to 19-year-olds although the differences between 13-year-olds to 15-year-olds and the reference group were non-significant, as was the case between 16-year-olds to 17-year-olds and the reference group as regard placenta praevia.

There were no statistically significant differences between the groups as regard PIH $(3.2 \% \quad(n=233)$ vs $4.2 \%(n=2158))$, chorioamnionitis $(0.6 \% \quad(n=44)$ vs $0.7 \%$ $(\mathrm{n}=377))$, sexually transmitted infections $(0.05 \% \quad(\mathrm{n}=10)$ vs $0.02 \%(n=34))$, bleeding in early pregnancy $(0.4 \%$ for both ( $n=27$ vs 190)), intrahepatic cholestasis of pregnancy $(1.1 \% \quad(n=79)$ vs $0.9 \% \quad(n=460))$ or fear of childbirth $(1.3 \%$ for both ( $\mathrm{n}=98$ vs 659$))$.

Regarding pregnancy complications among teenagers, we evaluated their effects on other adverse obstetric outcomes. Anaemia was a risk factor for very preterm birth (adjusted OR 2.1, 1.1 to 4.2). Proteinuria was found to be a risk factor for pre-eclampsia $(5.4,3.6$ to 8.0$)$, but not for eclampsia or adverse neonatal outcomes. UTI and pyelonephritis did not affect the risks of adverse obstetric outcomes.

\section{Delivery outcomes}

The estimated risks (adjusted OR) among all teenagers (13-19 years of age) compared with the reference women were: caesarean section 0.6 (0.6 to 0.7$)$, operative vaginal delivery $0.6(0.6$ to 0.7$)$ anal sphincter rupture 0.4 (0.3 to 0.5$)$ and breech presentation 0.7 (0.6 to 0.8 ) (figure 1). However, when analysed in subgroups according to age, the estimated risks among 13-year-olds to 15-year-olds did not differ significantly from those in the reference group, except for caesarean section.

The percentages of planned caesarean sections were similar among 13-year-olds to 15-year-olds and the reference women $(4.8 \%(n=4)$ vs $4.5 \% \quad(n=2301))$, but significantly lower among 16-17 and 18-year-olds to 19-year-olds $(2.4 \% \quad(n=30)$ and $3.2 \% \quad(n=192)$, respectively). Regarding urgent Caesarean sections, the frequencies were lower among all teenagers $(7.2 \% \quad(n=524)$ vs $11.7 \%(n=5996))$ and descended according to age. In the case of emergency caesarean sections, however, there were no significant differences $(1.1 \% \quad(n=83)$ vs $1.5 \%(\mathrm{n}=766))$.

The frequencies of induction of labour and use of oxytocin during labour were similar in the teenagers and reference women $(16.8 \% \quad(n=1226)$ vs $17.2 \% \quad(n=8788)$ and $49.7 \% \quad(n=3630)$ vs $50.3 \% \quad(n=25744)$, respectively). Episiotomy was performed less often in all teenage groups $(39.1 \%(n=2861)$ vs $41.2 \% \quad(n=21511))$, although the difference was non-significant as regard 13-year-olds to 15 -year-olds. Combined regional anaesthesia was used significantly more often in all teenage groups compared with the reference women $(72.5 \% \quad(n=5296)$ vs $66.3 \%$ $(\mathrm{n}=33$ 907)).

The incidence of uterine curettage after childbirth was lower among all 13-year-olds to 19-year-olds $(0.5 \% \quad(n=40)$ vs $0.9 \%(n=446))$, but the significance disappeared when the subgroups were analysed separately. Differences in the incidence of abnormal bleeding after childbirth were nonsignificant between 13-year-olds to 15-year-olds $(4.8 \%$ $(n=4))$ and the reference group $(3.5 \%(n=1772))$, but significantly lower among $16-17$ and 18-year-olds to 19-year-olds $(1.8 \% \quad(n=22)$ and $2.1 \% \quad(n=125)$, respectively). No differences were seen as regard shoulder dystocia $(0.2 \%$ for both ( $\mathrm{n}=9$ vs 116$)$, placental abruption $(0.2 \%$ for both ( $n=19$ vs 13$))$, uterine rupture (none vs $0.05 \%(n=24))$, abnormal bleeding during delivery $(0.2 \%$ for both ( $\mathrm{n}=3$ vs 135$))$ and postpartum infection $(0.5 \%$ $(\mathrm{n}=36)$ vs $0.4 \%(\mathrm{n}=229))$. 
Table 3 Maternal complications during pregnancy according to age group

\begin{tabular}{|c|c|c|c|c|c|}
\hline & \multicolumn{5}{|c|}{ Maternal age in years } \\
\hline & $13-15$ & $16-17$ & $18-19$ & All teenagers & $25-29$ \\
\hline $\mathrm{N}$ & 84 & 1234 & 5987 & 7305 & 51142 \\
\hline \multicolumn{6}{|l|}{ Anaemia ${ }^{\star M 1}$} \\
\hline n (\%) & $6(7.1)$ & $64(5.2)$ & $245(4.1)$ & $315(4.3)$ & $1227(2.4)$ \\
\hline OR $(95 \% \mathrm{Cl})$ & 3.2 (1.4 to 7.3$)$ & 2.3 (1.7 to 2.9$)$ & 1.8 (1.5 to 2.0$)$ & $1.9(1.7$ to 2.1$)$ & \\
\hline Adjusted OR (95\% Cl) & 3.1 (1.3 to 7.3$)$ & 2.2 (1.7 to 2.9$)$ & 1.8 (1.2 to 2.1$)$ & 1.8 (1.6 to 2.1$)$ & 1 (Ref.) \\
\hline \multicolumn{6}{|l|}{ Pre-eclampsia ${ }^{\mathrm{M} 2}$} \\
\hline n (\%) & $6(7.1)$ & $26(2.1)$ & $182(3.0)$ & 214 (2.9) & $1522(3.0)$ \\
\hline OR $(95 \% \mathrm{Cl})$ & $2.5(1.1$ to 5.8$)$ & $0.7(0.5$ to 1.0$)$ & 1.0 (0.9 to 1.2$)$ & $1.0(0.9$ to 1.1$)$ & \\
\hline Adjusted OR (95\% Cl) & 3.7 (1.5 to 9.0$)$ & $0.9(0.6$ to 1.4$)$ & $1.2(1.0$ to 1.5$)$ & $1.2(1.0$ to 1.4$)$ & 1 (Ref.) \\
\hline \multicolumn{6}{|l|}{ Eclampsia $^{\mathrm{M} 4}$} \\
\hline n (\%) & $0(0.0)$ & $2(0.2)$ & $9(0.2)$ & $11(0.2)$ & $26(0.1)$ \\
\hline OR $(95 \% \mathrm{Cl})$ & - & $3.2(0.8$ to 13.5$)$ & 3.9 (1.4 to 6.3$)$ & 3.0 (1.4 to 6.0$)$ & \\
\hline Adjusted OR (95\% Cl) & - & 2.3 (0.3 to 18.2$)$ & $3.3(1.4$ to 7.8$)$ & $3.2(1.4$ to 7.3$)$ & 1 (Ref.) \\
\hline \multicolumn{6}{|l|}{ Proteinuria ${ }^{\mathrm{M} 3}$} \\
\hline n (\%) & $2(2.4)$ & $9(0.7)$ & $32(0.5)$ & $43(0.6)$ & $171(0.3)$ \\
\hline OR $(95 \% \mathrm{Cl})$ & 7.3 (1.8 to 29.8$)$ & 2.2 (1.1 to 4.3$)$ & 1.6 (1.1 to 2.3$)$ & 1.8 (1.3 to 2.5$)$ & \\
\hline Adjusted OR (95\% Cl) & 12.3 (2.8 to 53.6$)$ & 2.4 (1.1 to 5.2$)$ & 1.6 (1.0 to 2.5$)$ & 1.8 (1.2 to 2.6$)$ & 1 (Ref.) \\
\hline \multicolumn{6}{|l|}{$\mathrm{UTI}^{\mathrm{M} 5}$} \\
\hline n (\%) & $0(0.0)$ & $6(0.5)$ & $21(0.4)$ & $27(0.4)$ & $75(0.1)$ \\
\hline OR $(95 \% \mathrm{Cl})$ & - & $3.3(1.4$ to 7.7$)$ & $2.4(1.5$ to 3.9$)$ & $2.5(1.6$ to 3.9$)$ & \\
\hline Adjusted OR (95\% Cl) & - & 4.1 (1.7 to 10.2$)$ & 2.7 (1.6 to 4.6$)$ & $2.9(1.8$ to 4.8$)$ & 1 (Ref.) \\
\hline \multicolumn{6}{|l|}{ Pyelonephritis $^{\mathrm{M} 6}$} \\
\hline $\mathrm{n}(\%)$ & $0(0.0)$ & $8(0.6)$ & $27(0.5)$ & $35(0.5)$ & $45(0.1)$ \\
\hline OR $(95 \% \mathrm{Cl})$ & - & 7.4 (3.5 to 15.8$)$ & 5.1 (3.2 to 8.3$)$ & 5.5 (3.5 to 8.5$)$ & \\
\hline Adjusted OR $(95 \% \mathrm{Cl})$ & - & 9.6 (4.2 to 21.9$)$ & 5.8 (3.4 to 10.0$)$ & 6.3 (3.8 to 10.4$)$ & 1 (Ref.) \\
\hline $\begin{array}{l}\text { All the variables are adjusted } \\
\text { M1: Demographic variables } \\
\text { M2: M1+(PIH and proteinuria } \\
\text { M3: M1+PIH. } \\
\text { M4: M3-misuse of alcohol o } \\
\text { M5: M1-misuse of alcohol o } \\
\text { M6: M1-pre-existing hyperte } \\
\text { *Haemoglobin < } 100 \text { g/L. } \\
\text { PIH, pregnancy-induced hyp }\end{array}$ & $\begin{array}{l}\text { rugs and pre-existing } \\
\text { rugs. } \\
\text { ion. } \\
\text { nsion; UTI, urinary tra }\end{array}$ & $\begin{array}{l}\text { odels: } \\
\text { ous abortions)+adec } \\
\text { pertension. } \\
\text { infection. }\end{array}$ & cy of prenatal care. & & \\
\hline
\end{tabular}

\section{Neonatal outcomes}

Table 4 summarises the incidences of various neonatal outcomes. No significant differences emerged between the 13-19 and 25-year-olds to 29-year-olds as regard 5 min Apgar score of less than $7(2.5 \% \quad(n=161)$ vs $2.8 \%$ $(\mathrm{n}=1213))$, cord blood $\mathrm{pH}$ below 7.05 at birth $(1.9 \%$
Figure 1 Frequencies (\%) of operative delivery and other delivery outcomes according to age group.

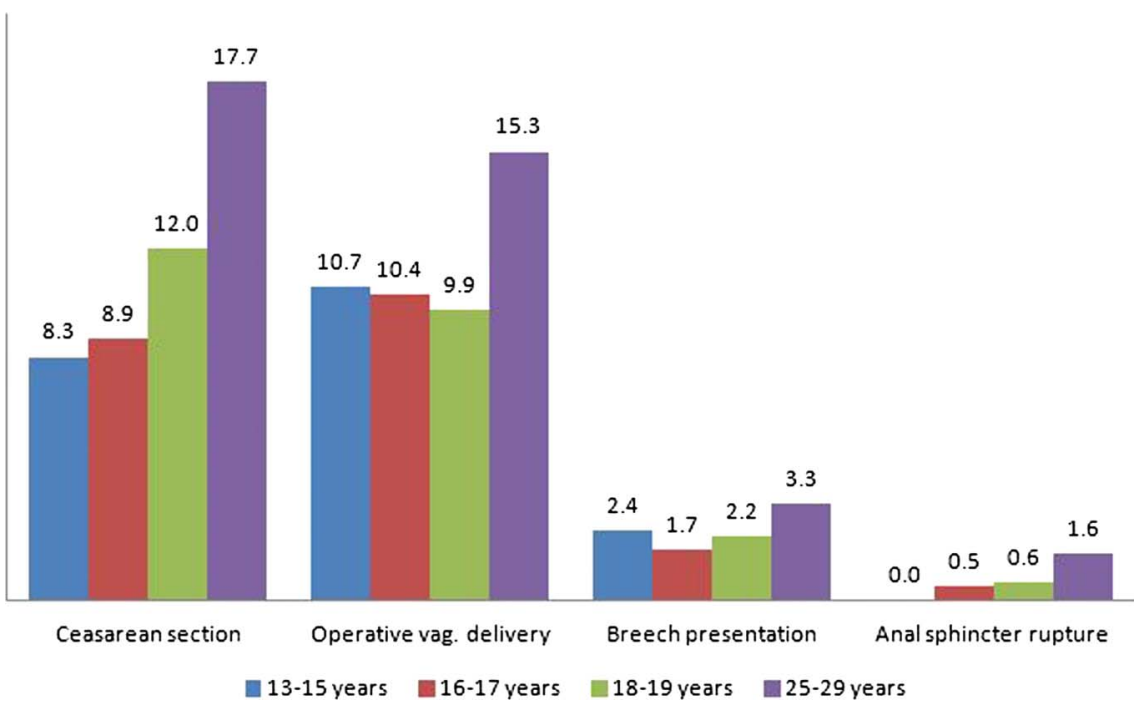


$(\mathrm{n}=139)$ vs $1.5 \%(\mathrm{n}=767))$, resuscitation of the newborn $(1 \%$ for both ( $\mathrm{n}=70$ vs 522$))$, use of a respirator $(1 \%$ $(n=74)$ vs $0.9 \%(n=456))$ or use of antibiotics $(6.6 \%$ $(\mathrm{n}=481)$ vs $6.8 \%(\mathrm{n}=3498))$.

\section{Adequacy of prenatal care}

To investigate the effect of low antenatal clinic attendance on obstetric outcomes, we performed a subgroup analysis of 210 teenagers with inadequate prenatal care compared with 6905 teenagers with adequate care. Teenagers with inadequate prenatal care were significantly more likely to be single $(33.3 \% \quad(n=67)$ vs $22.1 \%(n=1526), p<0.001)$ and to live in an urban area $(73.9 \%(\mathrm{n}=155)$ vs $66.4 \% \quad(\mathrm{n}=485)$, $\mathrm{p}=0.03$ ). Although the rate of smoking during pregnancy did not differ statistically significantly in the two groups (43.9\% ( $\mathrm{n}=92)$ vs $37.3 \%$ ( $\mathrm{n}=2576), \mathrm{p}=0.07)$, teenagers with inadequate prenatal care were less likely to quit smoking during the first trimester $(6.3 \% \quad(n=13)$ vs $12.8 \% \quad(n=884)$, $\mathrm{p}=0.008$ ). No significant differences between the groups emerged as regard being underweight $(11.4 \% \quad(\mathrm{n}=138)$ vs $10.4 \%(\mathrm{n}=718), \mathrm{p}=0.62)$ or obese $(4.7 \%(\mathrm{n}=10)$ vs $6.3 \%$ $(\mathrm{n}=435), \mathrm{p}=0.40)$, or misuse of alcohol or drugs during pregnancy $(0.5 \%(\mathrm{n}=1)$ vs $1.2 \% \quad(\mathrm{n}=81), \mathrm{p}=0.73)$.

Teenagers with inadequate prenatal care were at significantly higher risks of eclampsia and UTI, even after adjustment for confounding factors (table 5). No excess risks of delivery complications were seen. The increased risk of stillbirth and neonatal mortality was almost entirely explained by premature births among teenagers with inadequate prenatal care.

\section{DISCUSSION}

Our comprehensive population-based study indicated an increased risk of eclampsia, proteinuria, UTI, pyelonephritis and anaemia among pregnant teenagers. The youngest teenagers were also faced with a higher risk of pre-eclampsia. However, teenagers were more likely to deliver vaginally without delivery complications when compared with the reference women. Regarding neonatal outcomes, the risk of preterm birth was increased among the youngest teenagers, whereas older teenagers were at risk of having SGA infants. Inadequate prenatal care among teenagers increased the risks of eclampsia, UTI and several adverse neonatal outcomes. Confounding factors affected the risks of most neonatal outcomes, but their roles concerning maternal complications were less significant.

The registers used for our study are of high quality and have been shown to be in accordance with delivery

Table 4 Neonatal outcomes according to age group

\begin{tabular}{|c|c|c|c|c|c|}
\hline & \multicolumn{5}{|c|}{ Maternal age in years } \\
\hline & $13-15$ & $16-17$ & $18-19$ & All teenagers & $25-29$ \\
\hline $\mathrm{N}$ & 84 & 1234 & 5987 & 7305 & 51142 \\
\hline \multicolumn{6}{|c|}{ Extremely preterm $<28 w^{M 3}$} \\
\hline n (\%) & $2(2.4)$ & $3(0.2)$ & $23(0.4)$ & $28(0.4)$ & $149(0.3)$ \\
\hline OR $(95 \% \mathrm{Cl})$ & $8.5(2.1$ to 35.1$)$ & 0.8 (0.3 to 2.7$)$ & 1.3 (0.9 to 2.1$)$ & 1.3 (0.9 to 2.0$)$ & \\
\hline Adjusted OR (95\% Cl) & $5.4(0.7$ to 41.5$)$ & 0.3 (0.0 to 2.4$)$ & 1.1 (0.6 to 1.9$)$ & $1.0(0.6$ to 1.7$)$ & 1 (Ref.) \\
\hline \multicolumn{6}{|l|}{ Preterm $<37 w^{\mathrm{M} 2}$} \\
\hline n (\%) & $11(13.1)$ & $68(5.5)$ & $296(4.9)$ & $375(5.1)$ & $2440(4.8)$ \\
\hline OR $(95 \% \mathrm{Cl})$ & 3.0 (1.6 to 5.7$)$ & $1.1(0.9$ to 1.5$)$ & $1.0(0.9$ to 1.2$)$ & 1.1 (1.0 to 1.2$)$ & \\
\hline Adjusted OR (95\% Cl) & $2.5(1.2$ to 5.3$)$ & $1.0(0.8$ to 1.4$)$ & 0.9 (0.8 to 1.1$)$ & $1.0(0.8$ to 1.1$)$ & 1 (Ref.) \\
\hline \multicolumn{6}{|l|}{$\mathrm{SGA}^{\mathrm{M} 1}$} \\
\hline n (\%) & $2(2.4)$ & $52(4.2)$ & 199 (3.3) & $253(3.5)$ & $1262(2.5)$ \\
\hline OR $(95 \% \mathrm{Cl})$ & $0.9(0.2$ to 3.5$)$ & 1.7 (1.3 to 2.3$)$ & $1.4(1.2$ to 1.6$)$ & $1.4(1.2$ to 1.6$)$ & \\
\hline Adjusted OR (95\% Cl) & $0.5(0.1$ to 2.1$)$ & $1.2(0.9$ to 1.6$)$ & $1.0(0.8$ to 1.1$)$ & $1.0(0.8$ to 1.2$)$ & 1 (Ref.) \\
\hline \multicolumn{6}{|l|}{ Intensive care ${ }^{\mathrm{M} 4}$} \\
\hline n (\%) & $19(22.6)$ & $138(11.2)$ & 654 (10.9) & $811(11.1)$ & $5566(10.9)$ \\
\hline OR $(95 \% \mathrm{Cl})$ & $2.4(1.4$ to 4.0$)$ & 1.0 (0.9 to 1.2$)$ & $1.0(0.9$ to 1.1$)$ & $1.0(0.9$ to 1.1$)$ & \\
\hline Adjusted OR (95\% Cl) & $1.9(1.0$ to 3.4$)$ & $0.9(0.7$ to 1.1$)$ & 0.9 (0.8 to 1.0$)$ & $0.9(0.8$ to 1.0$)$ & 1 (Ref.) \\
\hline \multicolumn{6}{|l|}{ Stillbirth/neonatal death ${ }^{\mathrm{M} 5}$} \\
\hline n (\%) & $2(2.4)$ & $4(0.3)$ & $34(0.6)$ & $40(0.5)$ & $180(0.4)$ \\
\hline OR $(95 \% \mathrm{Cl})$ & 6.9 (1.7 to 28.3$)$ & 0.9 (0.3 to 2.5$)$ & 1.6 (1.1 to 2.3$)$ & 1.6 (1.1 to 2.2$)$ & \\
\hline Adjusted OR (95\% Cl) & $0.4(0.0 \text { to } 5.1)^{\mathrm{M} 6}$ & $0.6(0.1$ to 2.7$)$ & $1.4(0.8$ to 2.4$)$ & $1.2(0.7$ to 2.1$)$ & 1 (Ref.) \\
\hline
\end{tabular}

All the variables are adjusted according to multivariate models:

M1: Demographic variables (table 1-history of spontaneous abortions)+adequacy of prenatal care, gestational diabetes, $\mathrm{PIH}$, placental abruption, chorioamnionitis, pre-eclampsia, eclampsia.

M2: M1+anaemia+history of spontaneous abortions.

M3: M2-misuse of alcohol or drugs.

M4: M1+preterm birth and IUGR.

M5: M4-(misuse of alcohol or drugs and pre-existing hypertension).

M6: M5-(BMI and pre-existing diabetes).

BMI, body mass index; PIH, pregnancy-induced hypertension; SGA, small-for-gestational-age. 
Table 5 Maternal complications during pregnancy and neonatal outcomes according to adequacy of prenatal care

\begin{tabular}{|c|c|c|}
\hline & Inadequate prenatal care & Adequate prenatal care \\
\hline $\mathrm{N}$ & 210 & 6905 \\
\hline \multicolumn{3}{|l|}{ Pregnancy complications } \\
\hline \multicolumn{3}{|l|}{ Eclampsia $^{\mathrm{M} 4}$} \\
\hline n (\%) & $2(1.0)$ & $7(0.1)$ \\
\hline OR $(95 \% \mathrm{Cl})$ & 9.5 (2.0 to 45.9$)$ & \\
\hline Adjusted OR (95\% Cl) & 12.6 (2.6 to 62.6$)$ & 1 (Ref.) \\
\hline \multicolumn{3}{|l|}{$\mathrm{UTI}^{\mathrm{M} 3}$} \\
\hline$n(\%)$ & $3(1.4)$ & $24(0.3)$ \\
\hline OR $(95 \% \mathrm{Cl})$ & $4.2(1.2$ to 13.9$)$ & \\
\hline Adjusted OR (95\% Cl) & $5.8(1.7$ to 19.7$)$ & 1 (Ref.) \\
\hline \multicolumn{3}{|l|}{ Neonatal outcomes } \\
\hline \multicolumn{3}{|l|}{ Extremely preterm $<28 \mathrm{w}^{\mathrm{M} 6}$} \\
\hline n (\%) & $5(2.4)$ & $20(0.3)$ \\
\hline OR $(95 \% \mathrm{Cl})$ & 8.4 (3.1 to 22.6 ) & \\
\hline Adjusted OR (95\% Cl) & $0.7(0.1$ to 5.1$)$ & 1 (Ref.) \\
\hline \multicolumn{3}{|l|}{ Preterm $<37 w^{M 1}$} \\
\hline n (\%) & 35 (16.7) & $319(4.6)$ \\
\hline OR $(95 \% \mathrm{Cl})$ & 4.1 (2.8 to 6.0$)$ & \\
\hline Adjusted OR (95\% Cl) & $1.1(0.7$ to 1.7$)$ & 1 (Ref.) \\
\hline \multicolumn{3}{|l|}{ Apgar at $5 \mathrm{~min}<7^{\mathrm{M} 2}$} \\
\hline $\mathrm{n}(\%)$ & $10(5.8)$ & $140(2.3)$ \\
\hline OR $(95 \% \mathrm{Cl})$ & 2.7 (1.4 to 5.1$)$ & \\
\hline Adjusted OR (95\% Cl) & $1.9(0.8$ to 4.3$)$ & 1 (Ref.) \\
\hline \multicolumn{3}{|l|}{ Intensive care ${ }^{\mathrm{M} 2}$} \\
\hline $\mathrm{n}(\%)$ & $33(15.7)$ & $733(10.6)$ \\
\hline OR $(95 \% \mathrm{Cl})$ & 1.6 (1.1 to 2.3 ) & \\
\hline Adjusted OR (95\% Cl) & $1.0(0.6$ to 1.7$)$ & 1 (Ref.) \\
\hline \multicolumn{3}{|l|}{ Stillbirth/neonatal death ${ }^{\mathrm{M} 5}$} \\
\hline $\mathrm{n}(\%)$ & $5(2.4)$ & $28(0.4)$ \\
\hline OR $(95 \% \mathrm{Cl})$ & $6.0(2.3$ to 15.7$)$ & \\
\hline Adjusted OR $(95 \% \mathrm{Cl})$ & 0.7 (0.1 to 7.1$)$ & 1 (Ref.) \\
\hline \multicolumn{3}{|c|}{$\begin{array}{l}\text { All the variables are adjusted according to multivariate models: } \\
\text { M1: Demographic variables (Table 1-pre-existing hypertension and diabetes). } \\
\text { M2: M1+preterm birth-history of spontaneous abortions. } \\
\text { M3: M1-misuse of alcohol or drugs-history of spontaneous abortions. } \\
\text { M4: M1-misuse of alcohol or drugs, BMl and history of spontaneous abortions. } \\
\text { M5: M2-misuse of alcohol or drugs. } \\
\text { Missing data as regard confounding variables in inadequate versus adequate prenatal care group: cohabitation } 17.1 \% \text { versus } 9.7 \% \text {, smoking } \\
10 \% \text { versus } 2.2 \%, \text { BMI } 19.5 \% \text { versus } 2.1 \% \text {. } \\
\text { BMI, body mass index; UTI, urinary tract infection. }\end{array}$} \\
\hline
\end{tabular}

records. ${ }^{23}$ We were able to investigate the various factors that have been sparsely reported in connection with teenage pregnancies, such as proteinuria, UTI and pyelonephritis during pregnancy, fear of childbirth and pain relief during delivery. Our study was nationwide, giving a complete and realistic reflection of the situation regarding obstetric challenges among all teenage pregnancies during the study period.

In Finland, antenatal care, including routine visits to general practitioners and nurses/midwives, is provided free of charge by municipalities and used by virtually all pregnant women. ${ }^{28}$ Specialised maternity units in public hospitals take care of practically all obstetric patients and births. In addition, fetal screening including early ultrasonography with a nuchal translucency scan, blood tests and structural ultrasonography is offered to all pregnant women. ${ }^{29}$ Thus, the opportunity to receive comprehensive prenatal care is available to all regardless of socioeconomic status or residence. This minimises the confounding effects which often complicate studies of this kind. We also divided teenagers into categories by age. Although evidence suggests that the risks of neonatal problems are higher in younger, biologically immature adolescents, ${ }^{16-18}$ the majority of studies, especially those on maternal outcomes, have involved the use of a dichotomised study setting, neglecting the different stages of biological and psychological maturation in adolescents. ${ }^{10} 121930-35$ The importance of choosing the right reference group cannot be underestimated. The age of 20-24 years has often been used for reference, but age groups of even 20-39 years are seen. Childbearing has commonly been postponed in recent decades, in parallel with women's increasing level of education. The mean age of primigravid women in Finland was approximately 28 years during the study 
period; thus, we chose primigravid women of 25-29 years of age as a reference group.

Our study is retrospective, which remains a limitation. The reliability of the data depends on the accuracy of reporting. In addition, the database did not allow for identification of precise timing of the different events during pregnancy. There were more missing data regarding confounding effects in the teenage group, as in the subgroup of teenagers with inadequate prenatal care. We could not look at the socioeconomic or educational status of adolescents in this study. The MBR includes information on maternal occupation, which is, however, less relevant as regard teenagers and young adults. Unfortunately, there is no information on fathers in the MBR as a result of confidentiality rules. Had socioeconomic status been available for use in our multivariate models, this might have affected risks of adverse obstetric outcomes among teenagers. We were not able to obtain information on weight gain during pregnancy. Poor weight gain is a known risk factor of adverse neonatal outcomes, such as low birth weight. Our study group of 13-year-olds to 15-year-olds was small in number, thus leading to lack of power in detecting risks of rare outcomes. However, to discover the effect of very young age on the risk of adverse obstetric outcomes, this age group was analysed separately.

\section{Relevant results in relation to those of other studies}

Overall, there was a high rate of attendance at antenatal clinics, which was expected, as antenatal care is offered free of charge to all pregnant mothers. It can be speculated that women not reached by the antenatal care system may be socially disadvantaged in various areas of life. Poor socioeconomic status is often known to precede teenage pregnancy. ${ }^{36} 37$ This view is supported by our finding that teenagers smoked and were diagnosed with misuse of alcohol or drugs significantly more often than reference women. Similar findings come from many parts of the developed world,,$^{9} \quad 11 \quad 193839$ whereas early marriage and childbirth are more common in other, often developing parts of the world, thus leading to different social circumstances and possibly different pregnancy outcomes.

The increased risk of anaemia seen among teenagers is in accordance with findings from several earlier studies. ${ }^{10-12} 32$ Physical growth and menstruation results in an increase in iron requirements that is often not met by nutrition. This leads to a negative iron balance and makes teenagers more susceptible to anaemia during pregnancy. ${ }^{40}$ Poor fetal outcomes may occur, especially in cases of severe or first trimester anaemia. ${ }^{40}{ }^{41}$ In our study, anaemia was a risk factor of very preterm birth.

Previous studies carried out in industrialised countries have revealed no excess risks of pre-eclampsia or PIH among adolescents, ${ }^{9-12}{ }^{19}$ whereas higher risks have been reported in developing countries. ${ }^{14} 1534$ Our results are partly contradictory, indicating an increased risk of pre-eclampsia among the youngest teenagers. The relatively small number of pregnant mothers aged
13-15 years in our study places some uncertainty on this finding. A large Latin-American cross-sectional study revealed an increasing rate of pre-eclampsia with descending age, but there was no significant difference in risk after adjustment for confounding factors. ${ }^{17}$ A French study revealed a lower risk among teenagers, but the number of very young teenagers was even smaller than in the present study. ${ }^{11}$

Our results confirm findings in earlier studies, showing an elevated risk of eclampsia among pregnant teenagers. ${ }^{42}{ }^{43}$ A report by the National Center for Health Statistics in the USA showed an increasing trend in frequency with descending age $(0.6 \%$ in 10-year-olds to 14-year-olds and $0.3 \%$ among 25-year-olds to 29-year -olds). ${ }^{13}$ Owing to a smaller number of cases and rarity of the condition, we could not evaluate such a trend. The essential role of prenatal care in the prevention of eclampsia has been previously emphasised, ${ }^{44}$ although not in studies confined to teenagers. We found a marked 12-fold risk of eclampsia among teenagers with inadequate versus adequate care, highlighting the importance of adequate prenatal care in teenage pregnancies.

We found an increasing risk of proteinuria in pregnancy with descending age. An earlier study on the risk factors of proteinuria during pregnancy revealed a 1.5 -fold risk among women below the age of $20 .{ }^{45}$ Although the outcome of isolated proteinuria is mostly favourable, it is sometimes known to precede preeclampsia and even eclampsia ${ }^{46} 47$ and has been associated with preterm birth. ${ }^{48}$ Whether or not isolated proteinuria is part of the same disease spectrum as pre-eclampsia is controversial. ${ }^{45}{ }^{49}$ In our study, proteinuria was found to be a risk factor for pre-eclampsia, but not eclampsia or adverse neonatal outcomes.

Earlier studies on UTI and pyelonephritis in pregnant teenagers are sparse. Two UK studies reported 1.5-fold to 1.6-fold risks of $\mathrm{UTI}^{10}$ and pyelonephritis ${ }^{9}$ among all teenagers. In contrast, no excess risk was found in a Latin American study in which teenagers were analysed in subgroups by age. ${ }^{17}$ Our findings suggest higher risks of both UTI and pyelonephritis, with a trend towards a higher incidence with descending age. However, no cases were found among teenagers of 13-15 years of age, possibly because of the relative rarity of these diagnoses. Only a hypothesis for the reason behind the increased risks has been presented -reduced resistance to infections in pregnant teenagers. ${ }^{10}$ We speculate that teenagers might be sexually more active during pregnancy compared with older women, placing them at a higher risk of UTI. In addition, poorer recognition of symptoms of UTI could lead to delayed care and explain the increased risk of pyelonephritis.

UTIs, and pyelonephritis in particular, have been associated with higher risks of adverse neonatal outcomes, ${ }^{50} 51$ although they are preventable with early detection and antimicrobial care. ${ }^{52}$

Regarding other infections, our results do not support earlier findings of a higher risk of chorioamnionitis among adolescents compared with adult women. ${ }^{10} 12$ 
We detected lower or similar risks of delivery complications and a higher incidence of vaginal deliveries among teenagers, which is in line with findings in most studies in the developed world..$^{9-12} 19$ Contradictory findings derive mainly from studies in developing countries. ${ }^{17} 35$ The use of pain relief, especially combined regional anaesthesia, was high in all groups and was used even more often in teenagers compared with older women. This is in contrast to the results of a UK study. ${ }^{9}$

Three large retrospective cohort studies carried out in the USA and Latin America revealed 1.2-fold to 2-fold risks of preterm birth and 1.1-fold to 1.5-fold risks of SGA infants among teenagers, with an increasing trend with descending age. ${ }^{16-18}$ Elevated (1.5-fold) risks of stillbirth and/or neonatal death were found among the youngest teenagers. However, among older teenagers and after adjustment for gestational age, the risks were either lower or non-significant. ${ }^{16-18}$ These findings were largely confirmed in our study, although some differences were seen, possibly as a result of a smaller study population and the lack of socioeconomic status as a confounding factor. In addition, we found an excess risk of preterm birth only among the youngest teenagers. The lack of risk among older teenagers might be explained by the overall high quality and quantity of prenatal care in Finland.

In accordance with the results of several recent studies, ${ }^{20} 2153$ we found higher risks of adverse neonatal outcomes, including an excess risk of neonatal/infant mortality among teenagers with inadequate prenatal care.

\section{Unanswered questions and implications}

Our results add to existing literature, showing higher risks of various maternal complications among teenagers, often displaying an increasing trend with descending age. An increased risk of proteinuria during pregnancy was found, an outcome not analysed in past studies dealing with teenage pregnancy. Confirmation of this finding and its possible influence on other, more serious obstetric outcomes is required. The effect of prenatal care on maternal outcomes should also be further analysed in the future. Clinical studies on the mode of delivery and its complications would shed more light on whether or not adolescents have better myometrial function compared with older women or whether the higher incidence of uncomplicated vaginal births is a consequence of other factors, such as more attentive care of adolescents. In addition to immediate obstetric risks, studies on long-term consequences indicate a higher incidence of morbidity and preterm mortality among both teenage mothers and their children, ${ }^{124}$ and these risks should be examined in greater detail in the future.

The current study has practical implications: in addition to prevention and treatment of anaemia and eclampsia, screening and counselling in connection with proteinuria, UTI and pyelonephritis are important among pregnant adolescents. The higher risk of preeclampsia among the youngest teenagers should also be kept in mind. Teenagers in a welfare society are not a risk group as regard delivery complications, and neonatal outcomes are mainly good. However, the younger the expectant mother, the greater are the risks of several maternal and neonatal complications. Adequacy of prenatal care is of great importance in preventing serious adverse obstetric outcomes. Thus, extra efforts should be made to reach all pregnant teenagers and enroll them in adequate maternity care in early pregnancy.

Contributors $\mathrm{OH}, \mathrm{MG}$ and SL had the initial research idea and all authors contributed to the design, interpretation and critical revision of data. All authors had full access to the data and take responsibility of the integrity of the data and accuracy of the data analysis. SL carried out the analysis and wrote the drafts of the manuscript with important intellectual inputs from all coauthors. All authors have approved the final version of the manuscript submitted for publication. $\mathrm{OH}$ and SL act as guarantors.

Funding Financial support from Helsinki University Central Hospital Research Funds and Clinical Graduate School in Pediatrics/Gynecology, University of Helsinki, Finland are gratefully acknowledged.

\section{Competing interests None.}

Ethics approval The organisation responsible for the registers (THL National Institute for Health and Welfare) has given approval for the study (Dnro THL/ 1008/5.05.00/2012).

Provenance and peer review Not commissioned; externally peer reviewed.

Data sharing statement No additional data are available.

Open Access This is an Open Access article distributed in accordance with the Creative Commons Attribution Non Commercial (CC BY-NC 3.0) license, which permits others to distribute, remix, adapt, build upon this work noncommercially, and license their derivative works on different terms, provided the original work is properly cited and the use is non-commercial. See: http:// creativecommons.org/licenses/by-nc/3.0/

\section{REFERENCES}

1. Paranjothy $\mathrm{S}$, Broughton $\mathrm{H}$, Adappa $\mathrm{R}$, et al. Teenage pregnancy: who suffers? Arch Dis Child 2009;94:239-45.

2. E-Risk Study T. Teen-aged mothers in contemporary Britain. J Child Psychol Psychiatry 2002;43:727-42.

3. Olausson PO, Haglund B, Weitoft GR, et al. Teenage childbearing and long-term socioeconomic consequences: a case study in Sweden. Fam Plann Perspect 2001;33:70-4.

4. Otterblad Olausson P, Haglund B, Ringback Weitoft G, et al. Premature death among teenage mothers. BJOG 2004;111:793-9.

5. Olausson PO, Cnattingius $\mathrm{S}$, Haglund $\mathrm{B}$. Teenage pregnancies and risk of late fetal death and infant mortality. Br J Obstet Gynaecol 1999;106:116-21.

6. Perinatal statistics in the Nordic countries. Statistical Report 7/2012. [updated 2012 March 27; cited 2013 Apr 10]. Official Statistics of Finland, Health 2012. THL. http://www.thl.fi/en US/web/en/statistics/ topics/reproductive_health/deliveries

7. Birth summary tables, England and Wales-2010. [cited 2013 Aug 10]. http://www.statistics.gov.uk/hub/population/births-and-fertility/ live-births-and-stillbirths

8. Hamilton BE, Ventura SJ. Birth rates for U.S. teenagers reach historic lows for all age and ethnic groups. NCHS data brief, no 89 Hyattsville, MD: National Center for Health Statistics, 2012.

9. Gupta N, Kiran U, Bhal K. Teenage pregnancies: obstetric characteristics and outcome. Eur J Obstet Gynecol Reprod Biol 2008;137:165-71.

10. Jolly MC, Sebire N, Harris J, et al. Obstetric risks of pregnancy in women less than 18 years old. Obstet Gynecol 2000;96:962-6.

11. de Vienne CM, Creveuil C, Dreyfus M. Does young maternal age increase the risk of adverse obstetric, fetal and neonatal outcomes: a cohort study. Eur J Obstet Gynecol Reprod Biol 2009;147:151-6.

12. Raatikainen K, Heiskanen N, Verkasalo PK, et al. Good outcome of teenage pregnancies in high-quality maternity care. Eur J Public Health 2006;16:157-61. 
13. Menacker F, Martin JA, MacDorman MF, et al. Births to 10-14 year-old mothers, 1990-2002: trends and health outcomes. Natl Vital Stat Rep 2004;53:1-18.

14. Rasheed S, Abdelmonem A, Amin M. Adolescent pregnancy in Upper Egypt. Int J Gynaecol Obstet 2011;112:21-4.

15. Usta IM, Zoorob D, Abu-Musa A, et al. Obstetric outcome of teenage pregnancies compared with adult pregnancies. Acta Obstet Gynecol Scand 2008;87:178-83.

16. Chen XK, Wen SW, Fleming $\mathrm{N}$, et al. Teenage pregnancy and adverse birth outcomes: a large population based retrospective cohort study. Int J Epidemiol 2007;36:368-73.

17. Conde-Agudelo A, Belizan JM, Lammers C. Maternal-perinatal morbidity and mortality associated with adolescent pregnancy in Latin America: cross-sectional study. Am J Obstet Gynecol 2005;192:342-9.

18. Malabarey OT, Balayla J, Klam SL, et al. Pregnancies in young adolescent mothers: a population-based study on 37 million births. J Pediatr Adolesc Gynecol 2012;25:98-102.

19. Fleming $\mathrm{N}, \mathrm{Ng} \mathrm{N}$, Osborne $\mathrm{C}$, et al. Adolescent pregnancy outcomes in the province of Ontario: a cohort study. J Obstet Gynaecol Can 2013;35:234-45.

20. Vieira CL, Coeli CM, Pinheiro RS, et al. Modifying effect of prenatal care on the association between young maternal age and adverse birth outcomes. J Pediatr Adolesc Gynecol 2012;25:185-9.

21. Debiec KE, Paul KJ, Mitchell CM, et al. Inadequate prenatal care and risk of preterm delivery among adolescents: a retrospective study over 10 years. Am J Obstet Gynecol 2010;203:122.e1-6.

22. Congenital anomalies 1993-2010. Statistical report 1/2013. [updated 2013 January 15; cited 2013 June 24]. Official Statistics of Finland, Congenital Malformations. THL. http://www.thl.fi/en_US/web/en/ statistics/topics/reproductive health/congenital anomalies

23. Gissler M, Haukka J. Finnish health and social welfare registers in epidemiological research. Norsk Epidemiol 2004;14:113-20.

24. Gissler M, Teperi J, Hemminki E, et al. Data quality after restructuring a nationwide medical birth registry. Scand J Soc Med 1995;23:75-80.

25. Pihkala J, Hakala T, Voutilainen $P$, et al. [Characteristics of recent fetal growth curves in Finland]. Duodecim 1989;105:1540-6. Finnish.

26. Statistic Finland. Tilastokeskus-Statistikcentralen-Statistics Finland. 2012 [updated 2012 March 27; cited 2013 Aug 10]. http:// www.tilastokeskus.fi/index en.html

27. Viisainen K. [Screening and collaboration in Maternity care. Guidelines 1999.]. Jyväskylä: STAKES Oppaita 34; 1999. Finnish.

28. Perinatal statistics: parturients, deliveries and newborns 2011. Statistical Report 20/2012. [updated 2012 Dec 12; cited 2013 Apr 10]. Official Statistics of Finland, Health 2012. THL. http://www.thl.fi/ en US/web/en/statistics/topics/reproductive health/deliveries

29. FINLEX. Government Degree on Screenings act 1339/2006. 2006 [cited 2013 Aug 10]. http://www.finlex.fi/en/

30. Bradford JA, Giles WB. Teenage pregnancy in western Sydney. Aust N Z J Obstet Gynaecol 1989;29:1-4

31. Abu-Heija A, Ali AM, Al-Dakheil S. Obstetrics and perinatal outcome of adolescent nulliparous pregnant women. Gynecol Obstet Invest 2002;53:90-2.

32. Briggs MM, Hopman WM, Jamieson MA. Comparing pregnancy in adolescents and adults: obstetric outcomes and prevalence of anemia. J Obstet Gynaecol Can 2007;29:546-55.

33. Brown HL, Fan YD, Gonsoulin WJ. Obstetric complications in young teenagers. South Med J 1991;84:46-8.
34. Mahavarkar SH, Madhu CK, Mule VD. A comparative study of teenage pregnancy. J Obstet Gynaecol 2008;28:604-7.

35. Sagili H, Pramya N, Prabhu K, et al. Are teenage pregnancies at high risk? A comparison study in a developing country. Arch Gynecol Obstet 2012;285:573-7.

36. Imamura $\mathrm{M}$, Tucker J, Hannaford $\mathrm{P}$, et al. Factors associated with teenage pregnancy in the European Union countries: a systematic review. Eur J Public Health 2007;17:630-6.

37. Vikat A, Rimpela A, Kosunen E, et al. Sociodemographic differences in the occurrence of teenage pregnancies in Finland in 1987-1998: a follow up study. J Epidemiol Community Health 2002;56:659-68.

38. Cavazos-Rehg PA, Krauss MJ, Spitznagel EL, et al. Brief report: pregnant by age 15 years and substance use initiation among US adolescent girls. J Adolesc 2012;35:1393-7.

39. Hansen BT, Kjaer SK, Munk C, et al. Early smoking initiation, sexual behavior and reproductive health-a large population-based study of Nordic women. Prev Med 2010;51:68-72.

40. Beard JL. Iron requirements in adolescent females. J Nutr 2000;130 (Suppl 2S):440S-2S.

41. Scanlon KS, Yip R, Schieve LA, et al. High and low hemoglobin levels during pregnancy: differential risks for preterm birth and small for gestational age. Obstet Gynecol 2000;96:741-8.

42. Morikawa M, Cho K, Yamada T, et al. Risk factors for eclampsia in Japan between 2005 and 2009. Int J Gynaecol Obstet 2012;117:66-8.

43. Tebeu PM, Halle G, Lemogoum D, et al. Risk factors for eclampsia among patients with pregnancy-related hypertension at Maroua Regional Hospital, Cameroon. Int J Gynaecol Obstet 2012;118:254-6.

44. Ansari MZ, Mueller BA, Krohn MA. Epidemiology of eclampsia. Eur $J$ Epidemiol 1995;11:447-51.

45. Macdonald-Wallis C, Lawlor DA, Heron J, et al. Relationships of risk factors for pre-eclampsia with patterns of occurrence of isolated gestational proteinuria during normal term pregnancy. PLoS ONE 2011;6:e22115.

46. Knight M, UKOSS. Eclampsia in the United Kingdom 2005. BJOG 2007;114:1072-8.

47. Morikawa M, Yamada T, Minakami H. Outcome of pregnancy in patients with isolated proteinuria. Curr Opin Obstet Gynecol 2009;21:491-5.

48. Franceschini N, Savitz DA, Kaufman JS, et al. Maternal urine albumin excretion and pregnancy outcome. Am J Kidney Dis 2005;45:1010-18

49. Masuyama $\mathrm{H}$, Suwaki $\mathrm{N}$, Nakatsukasa $\mathrm{H}$, et al. Circulating angiogenic factors in preeclampsia, gestational proteinuria, and preeclampsia superimposed on chronic glomerulonephritis. $\mathrm{Am} J$ Obstet Gynecol 2006;194:551-6.

50. Mittal $P$, Wing DA. Urinary tract infections in pregnancy. Clin Perinatol 2005;32:749-64.

51. Farkash E, Weintraub AY, Sergienko R, et al. Acute antepartum pyelonephritis in pregnancy: a critical analysis of risk factors and outcomes. Eur J Obstet Gynecol Reprod Biol 2012;162:24-7.

52. Romero R, Oyarzun E, Mazor M, et al. Meta-analysis of the relationship between asymptomatic bacteriuria and preterm delivery/ low birth weight. Obstet Gynecol 1989;73:576-82

53. Partridge S, Balayla J, Holcroft CA, et al. Inadequate prenatal care utilization and risks of infant mortality and poor birth outcome: a retrospective analysis of $28,729,765$ U.S. deliveries over 8 years. Am J Perinatol 2012;29:787-93. 